\title{
Effects of Oral Commensal Streptococci on Porphyromonas gingivalis Invasion into Oral Epithelial Cells
}

\author{
Alyssa N. Hanel ${ }^{1,2}$, Hannah M. Herzog ${ }^{1}$, Michelle G. James ${ }^{1}$ and Giancarlo A. Cuadra ${ }^{1, *}$ \\ 1 Department of Biology, Muhlenberg College, 2400 W. Chew Street, Allentown, PA 18104, USA; \\ ah3573@cumc.columbia.edu (A.N.H.); hmherzog@muhlenberg.edu (H.M.H.); \\ mgjames@muhlenberg.edu (M.G.J.) \\ 2 College of Dental Medicine, Columbia University, 622 W 168th St, New York, NY 10032, USA \\ * Correspondence: giancarlocuadra@muhlenberg.edu; Tel.: +1-484-664-3256
}

Received: 5 April 2020; Accepted: 30 April 2020; Published: 2 May 2020

\begin{abstract}
The objective of this study was to determine if the interaction between common oral commensal bacteria and oral epithelial cells would provide protective effects against the invasion of periodontopathogen Porphyromonas gingivalis. Oral epithelial OKF6/Tert cells were used in co-cultures with Streptococcus gordonii, Streptococcus oralis, Streptococcus mitis, and Streptococcus intermedius. The viability of OKF6/Tert cells following a bacterial challenge was evaluated by trypan blue exclusion. The adherence of commensal species was determined by CFU counts. P. gingivalis invasion in OKF6/Tert cells was assessed before and after exposure to commensal species according to CFU counts. Viability assays show that only $S$. gordonii and $S$. intermedius display low toxicity toward OKF6/Tert cells. Both commensals adhere to OKF6/Tert cells at an average ratio of 1 CFU to 10 cells. P. gingivalis invasion into host cells is significantly reduced by $25 \%$ or $60 \%$ after exposure to S. gordonii or $S$. intermedius, respectively. The results suggest that these commensal species bind to host cells and diminish $P$. gingivalis invasion. This is important in the context of periodontal disease since $P$. gingivalis primarily acts on the host by invading it. Therefore, efforts to decrease invasion will eventually lead to future therapies harnessing the mechanisms employed by oral commensal bacteria.
\end{abstract}

Keywords: oral; commensal; streptococci; P. gingivalis; invasion; protection

\section{Introduction}

Periodontal disease (PD) is an oral inflammatory condition induced by the diffusion of bacteria into the epithelium surrounding the tooth. PD affects $47.2 \%$ of adults over the age of 30 in some capacity, and approximately $70.1 \%$ of adults 65 years of age and older have a form of PD [1]. This is exceedingly important, as the number of adults aged 65 and older is increasing markedly and periodontal health is a key contributor to systemic health [2]. PD can cause tooth loss, pain, discomfort and difficulty speaking, chewing and swallowing, which could ultimately lead to poor nutrition [2]. The first stage of PD is caused by a disruption of bacterial homeostasis in the areas that surround and support the tooth, leading to the inflammation and infection of the gums, or gingivitis [3]. The inflammation associated with gingivitis and periodontitis can lead to a proliferation and dilation of the vasculature, which provide a greater opportunity for oral bacteria to enter the bloodstream. While this bacteremia is often transient, it has the potential to reach a variety of target organs [4]. Bacteria that originate in the oral cavity are also associated with several severe systemic conditions including cardiovascular disease [5,6], respiratory infections [7], arthritis [8], diabetes [9,10], and Alzheimer's disease [11,12].

The oral cavity contains a rich microbiota which, in healthy individuals, remains in homeostasis. The health of periodontal tissues is determined by the composition of this microbiota and the 
antagonistic and synergistic relationships therein [13]. Pathogenic bacteria within this microbial environment lead to tissue destruction by subverting the host immune response and disrupting the microbial-host homeostasis [14]. Gram-negative anaerobes, most notably Porphyromonas gingivalis, are found in large quantities in the subgingival sulcus of patients suffering from periodontitis [15]. Growing evidence suggests that these pathogens have an exceedingly complex relationship with both the host [16] and the nearby commensal microbiota $[17,18]$. In healthy individuals, several species of streptococci take part in the early colonization of the oral cavity by inhibiting the growth of pathogenic bacteria $[19,20]$. For instance, Streptococcus gordonii, which is regarded as a species of commensal bacteria, is found more frequently in healthy tissue than in areas affected by PD. This commensal species does not alter transcription in oral epithelial cells as significantly as pathogenic strains [21,22]. S. gordonii is one of the first species to re-colonize after brushing or antibacterial rinses, which makes it a candidate for the exclusion of pathogenic microbes from tooth surfaces. In fact, oral streptococci constitute over $80 \%$ of early oral biofilm and plaque [23]. Commensal streptococci include several groups with multiple species. Examples of these groups and species are the Anginosus group (Streptococcus intermedius), Sanguinis group (Streptococcus gordonii), and Mitis group (Streptococcus mitis and Streptococcus oralis) [24]. The four species mentioned have been found to be ubiquitous in healthy and PD-affected individuals [25].

P. gingivalis has been studied extensively in the context of its role in the progression of PD. This pathogen is known to adhere to and invade both monolayers and multilayers of primary gingival epithelial cells (GEC) [26-29] The adherence of $P$. gingivalis is mediated by the major fimbriae, a key virulence factor [30]. Fimbrillin (FimA), a subunit of these filamentous components, interacts with both the host tissue and other bacteria to allow for association [30]. $\beta 1$ integrins have been identified as epithelial cell cognate receptors for these P. gingivalis fimbriae [29]. After P. gingivalis initially adheres, with the predominant adhesins being the major fimbriae, an integrin-associated signaling cascade is initiated. Actin microfilaments and microtubule structures in the cell accommodate the entry of the bacteria. This, along with the recruitment of lipid raft components and host-cell signaling events, is required for the internalization of $P$. gingivalis [15]. Once $P$. gingivalis invades, several virulence factors including FimA, RgpA/B and Kgp show decreased expression, and stress-associated proteins such as peroxidases and heat shock proteins are upregulated [15]. These changes result from a need for $P$. gingivalis to adapt to the intracellular environment.

ArcA is a conserved gene found in several oral commensal species and encodes for arginine deaminase [31]. Some studies have investigated ArcA as a factor that potentially inhibits the interactions of $P$. gingivalis with the host tissue, disrupting the progression of periodontal disease. For instance, Streptococcus cristatus ArcA interferes with the colonization of P. gingivalis in mice [32]. Similarly, arginine deaminase of oral streptococci like S. cristatus and S. intermedius downregulates the expression of FimA in P. gingivalis, which allows for biofilm formation [13,31,33,34]. In addition, commensal bacteria including S. gordonii, S. mitis and S. intermedius were capable of antagonizing the growth of pathogenic species including $P$. gingivalis [20,35]. $\mathrm{H}_{2} \mathrm{O}_{2}$ released by these streptococci appeared to be the most prevalent antimicrobial substance that inhibited the growth of the pathogens $[20,36]$.

The invasive capabilities of commensal streptococci have not been investigated to a great extent. S. intermedius interacts with and, to a certain extent, seems to invade hepatic cell models [37]. While S. gordonii is known to invade endothelial cells [38], it does not exhibit detectable invasion of gingival epithelial cell (GEC) multilayers [26]. Previous research suggests that S. gordonii has the ability to invade human aortic endothelial cells [38], but to date, there is scant research regarding the invasion of S. gordonii or any other commensal strain into oral epithelial cells. Conversely, S. gordonii tends to induce an immune response in GECs, leading to the secretion of IL-1B, IL-6, IL-8 and TNF- $\alpha$ and ultimately contributing to gingival health via immunosurveillance [26]. Additionally, this commensal improved paracellular barrier function by increasing the expression of genes encoding the tight junction components ZO-1, ZO-2, JAM-A, and occludin [39]. 
To date, it remains unclear if commensal bacteria can interfere with the ability of $P$. gingivalis to invade host cells. If so, this means that the commensal bacteria promote a protective effect in the context of pathogenic invasion. The aim of this study is to determine whether commensal bacteria can slow $P$. gingivalis invasion into host cells in sequential co-cultures. We are investigating the effect of a pre-exposure to commensal bacteria on oral epithelial cells to determine if that interaction protects epithelial cells from a subsequent $P$. gingivalis invasion. We hypothesize that the interaction between commensal bacteria and oral epithelial cells will directly hinder $P$. gingivalis invasion.

\section{Materials and Methods}

\subsection{Cell Line and Bacterial Cultures}

The immortal human oral keratinocyte OKF6/Tert cell line was kindly provided by Dr. Gill Diamond from the University of Florida, College of Dentistry (Gainesville, FL, USA) [40]. Cells were cultured in tissue culture plates at $37{ }^{\circ} \mathrm{C}$ in $5 \% \mathrm{CO}_{2}$ (standard conditions) with complete Keratinocyte Serum-Free Growth Medium (KSFM) prepared following the methods described by Brice et al. [40]. Briefly, KSFM base medium plus $30 \mu \mathrm{g} / \mathrm{mL}$ of bovine pituitary extract, $0.3 \mathrm{mM}$ calcium chloride, $1 \mathrm{mM}$ glutamine, and $100 \mathrm{U} / \mathrm{mL}$ of penicillin and streptomycin was used. Cells were sub-cultured every 4 to 6 days. All experiments were conducted between passages 21 and 37.

Streptococcus gordonii DL1, Streptococcus intermedius 0809, Streptococcus mitis UF2, and Streptococcus oralis SK139 were grown in Brain Heart Infusion Broth (BHI) with $5 \mu \mathrm{g} / \mathrm{mL}$ hemin or in BHI agar at $37{ }^{\circ} \mathrm{C}$ in $5 \% \mathrm{CO}_{2}$ (standard conditions). All four commensal species were kindly provided by Dr. Robert Burne from the University of Florida, College of Dentistry (Gainesville, FL, USA). Porphyromonas gingivalis 33277 was kindly provided by Dr. Richard Lamont at the University of Louisville, School of Dentistry (Louisville, KY, USA). P. gingivalis 33277 was grown in Trypticase soy broth with yeast extract $(1 \mathrm{mg} / \mathrm{mL})$, hemin $(5 \mu \mathrm{g} / \mathrm{mL})$, and menadione $(1 \mu \mathrm{g} / \mathrm{mL})$ (TSBY) or in blood agar with menadione $(1 \mu \mathrm{g} / \mathrm{mL})$ anaerobically at $37^{\circ} \mathrm{C}$ in a Bactron 300 anaerobic incubator from Sheldon Manufacturing, Inc. (Cornelius, OR, USA).

\subsection{Bacterial Growth Curves}

Starter cultures of S. gordonii DL1, S. mitis UF2, S. intermedius 0809, and S. oralis SK139 were grown in BHI media overnight at $37{ }^{\circ} \mathrm{C}$ in $5 \% \mathrm{CO}_{2}$. The following day, starter cultures were adjusted to $\mathrm{OD}_{595 \mathrm{~nm}}=1.0$, and $1 \%$ inoculum was used to grow new cultures in BHI and KSFM without antibiotics. The cultures were incubated at $37^{\circ} \mathrm{C}$ in $5 \% \mathrm{CO}_{2}$, and absorbance was read every $2 \mathrm{~h}$ for $12 \mathrm{~h}$ and at $24 \mathrm{~h}$ post-inoculation.

\subsection{Streptococcal Cytotoxicity Assay}

OKF6/Tert cells were grown in 12-well plates with $1 \mathrm{~mL}$ of complete KSFM/well to at least $90 \%$ confluency. Streptococci were grown to late exponential phase, and cultures of each species were adjusted to $\mathrm{OD}_{595 \mathrm{~nm}}=1.0$. Bacteria were diluted separately in antibiotic-free KSFM. OKF6/Tert cells were washed three times with $1 \mathrm{~mL}$ of sterile PBS per well to remove excess antibiotics. Bacteria in their spent media were diluted in antibiotic-free KSFM to ensure that the microbes and their products were involved in all assays, mimicking in vivo interactions as close as possible. After diluting, all streptococcal strains and their extracellular products were added to OKF6/Tert cells at a multiplicity of infection (MOI) of 100 in a final volume of $1 \mathrm{~mL}$ in separate wells. In addition, matching volumes of filtered-sterile spent BHI media were diluted in KSFM, or KSFM alone was added to OKF6/Tert cells as controls for cytotoxicity. All co-cultures and corresponding controls were then incubated for 1 or $2 \mathrm{~h}$ post-infection under standard conditions. Then, OKF6/Tert cells were washed three times with $1 \mathrm{~mL}$ of sterile PBS per well to remove unbound streptococci, and an antibiotic protection assay was performed. Briefly, OKF6/Tert cells were incubated for an hour with $1 \mathrm{~mL}$ of KSFM containing $300 \mu \mathrm{g} / \mathrm{mL}$ of gentamicin and $200 \mu \mathrm{g} / \mathrm{mL}$ of metronidazole to kill extracellular bacteria [27-29,41,42]. Then, cultures were incubated 
for $48 \mathrm{~h}$ post-infection in complete KSFM (containing penicillin and streptomycin) under standard conditions. To assess cellular morphology during and after host-bacteria interactions, images of the keratinocyte monolayers were acquired at 200X magnification using a Nikon Eclipse TE2000-U inverted microscope equipped with a Nikon Digital Sight DS-Fi1 camera and NIS Elements Imagine Software (Nikon Instruments Inc, Melvin, NY, USA) at indicated time-points. After $48 \mathrm{~h}$ post-infection, cells were trypsinized and mixed with an equal volume of trypan blue, which diffuses inside dead cells, thus staining them blue under the light microscope. Live (unstained) cells were counted using the hemocytometer and light microscopy.

\subsection{Streptococcal Adherence and Invasion Assays}

Co-cultures of OKF6/Tert cells with either S. gordonii DL1 or S. intermedius 0809 at MOI $=100$ were incubated for $1 \mathrm{~h}$ as above. Excess bacteria were then washed three times with $1 \mathrm{~mL}$ of PBS per well, and OKF6/Tert cells were either lysed with $1 \mathrm{~mL}$ of sterile $\mathrm{diH}_{2} \mathrm{O}$ per well or subjected to an antibiotic protection assay as described above. After the hour of killing, OKF6/Tert cells were washed and lysed as above. Lysates before and after the antibiotic protection assay were plated on BHI agar for CFU counts to quantify commensal bacteria adherence and invasion, respectively.

\subsection{P. gingivalis Invasion Assays}

OKF6/Tert cells were incubated for $1 \mathrm{~h}$ with either S. gordonii DL1 or S. intermedius 0809 as above. Then, cells were washed three times with $1 \mathrm{~mL}$ of PBS per well to remove excess commensal bacteria. To ensure the streptococci that adhered to the OKF6/Tert cells remained alive, no antibiotic protection assay was performed at this point. The $P$. gingivalis 33277 overnight culture was adjusted to $\mathrm{OD}=1.0$, diluted in antibiotic-free KSFM, and added to cells pre-exposed to streptococci at MOI $=100$. Equal quantities of $P$. gingivalis 33277 were also added to OKF6/Tert cells that were not exposed to streptococci (control). Co-cultures were incubated for $30 \mathrm{~min}$ under standard conditions [28,43]. Then, cells were washed three times with $1 \mathrm{~mL}$ of PBS per well, and an antibiotic protection assay was performed to kill all extracellular bacteria, as described above. Cells were washed and lysed as indicated above. Lysates were serially diluted in sterile PBS, plated on blood agar plates with menadione, and incubated for about 5 days anaerobically before counting $P$. gingivalis colonies.

\subsection{Streptococcal Inhibition of P. gingivalis Growth}

Growth inhibition experiments were conducted following the methodology of Herrero et al. [20]. Escherichia coli does not have any effect on P. gingivalis growth [20] and therefore was used as a negative control for inhibition experiments. Late exponential phase cultures of S. gordonii DL1, S. intermedius 0809, and E. coli OP50 grown in BHI (OD = 1.0) were diluted to 1:100 in TSBY. Ten microliters of each strain were plated on separate blood agar plates with $1 \mu \mathrm{g} / \mathrm{mL}$ of menadione and allowed to dry. Bacteria were cultured for 24 h. P. gingivalis was grown overnight in TSBY anaerobically, the OD was adjusted to 1.0, the cultures were diluted 1:10 in TSBY, and $10 \mu \mathrm{L}$ were plated on the same blood agar approximately $1 \mathrm{~mm}$ away from the spots of the already existing strains. Bacteria were cultured for about three days anaerobically, and the plates were photographed to observe P. gingivalis growth patterns.

\subsection{Statistical Analyses}

Every experiment was repeated at least three times. Figures represent the mean and standard deviation of the data. T-tests and ANOVAs were performed, and $p$ values $<0.05$ were noted as significant. 


\section{Results}

\subsection{KSFM Supports Growth of Commensal Bacteria}

In order to compare growth patterns, all commensals were grown in BHI and KSFM without antibiotics. As shown in Figure 1, S. gordonii had the most rapid growth in BHI, followed by S. mitis, S. oralis and S. intermedius. S. gordonii and S. mitis entered the exponential phase of growth by $2 \mathrm{~h}$ and continued growing, reaching the late-exponential phase at $4 \mathrm{~h}$. For these species, the stationary phase lasted from Hour 4 to the end of the experiment (Figure 1). S. oralis grew exponentially from Hours 2 to 6 and then continued into the stationary phase for the remainder of the experiment (Figure 1). $S$. intermedius reached the end of exponential phase at $12 \mathrm{~h}$. Similar growth patterns were observed in KSFM. However, for all species, absorbance values throughout the experiment remained below 0.5 in this medium. Once again, S. gordonii and S. mitis grew the fastest in KSFM compared to the other two species (Figure 1). S. intermedius also experienced the slowest growth in KSFM. Our data indicate that these four streptococci are not harmed in KSFM. This cell culture medium supports their growth but to a limited absorbance value when compared to growth in BHI broth (Figure 1).

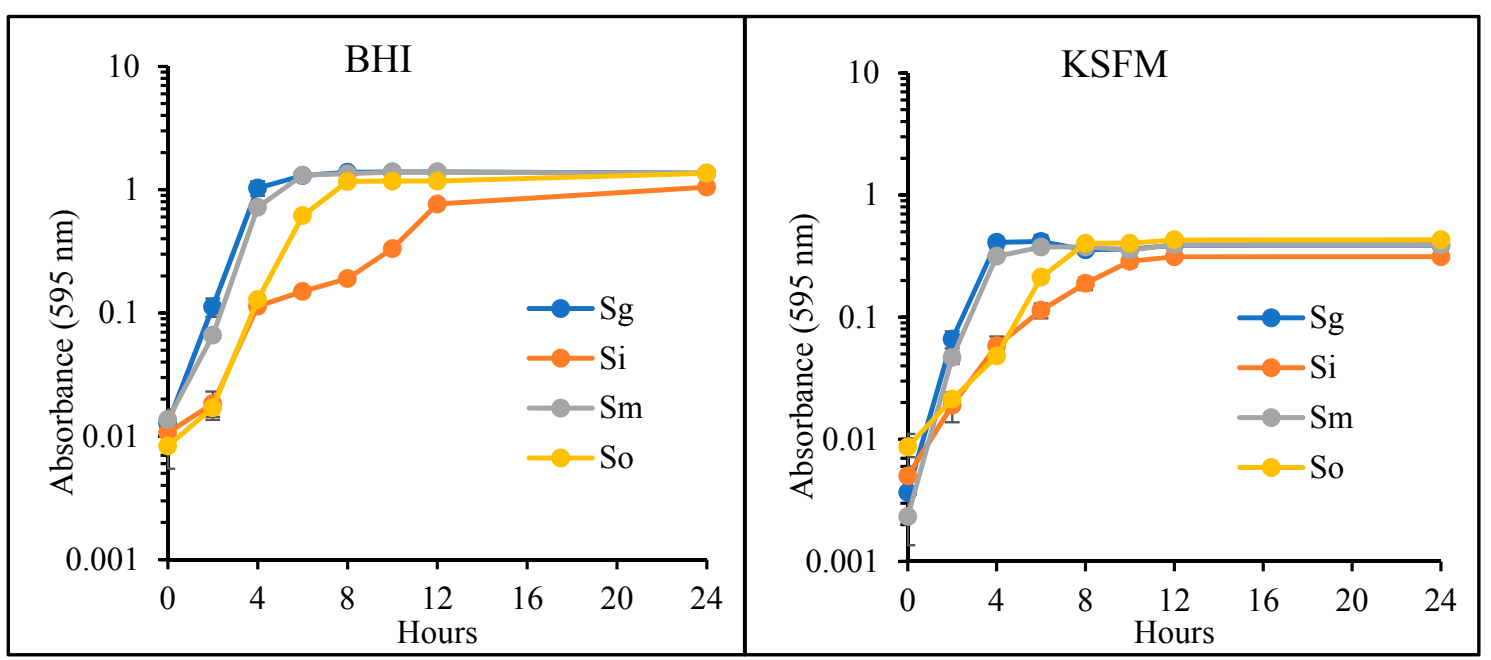

Figure 1. Growth of commensal bacteria in Brain Heart Infusion Broth (BHI) and Keratinocyte Serum-Free Growth Medium (KSFM). S. gordonii (Sg), S. intermedius (Si), S. mitis (Sm) and S. oralis (So) were grown in KSFM and BHI. Absorbance was measured at indicated time-points $(n=3)$.

\subsection{OKF6 Cell Viability after Commensal Challenge}

Prior to any further studies, we determined the periods of time for which OKF6/Tert cells can withstand each of the oral streptococci at MOI $=100$. Figure 2 shows the cellular morphology at 0 , 24 and $48 \mathrm{~h}$ after exposure with all four commensals for $1 \mathrm{~h}$ of host-bacteria interactions in 24 -well plates. The results show that the cells were nearly $100 \%$ confluent at the time of exposure to bacteria and remained at high confluency until $48 \mathrm{~h}$ post-exposure. The cellular morphology seems to be intact, but some cellular changes begin to appear after exposure to $S$. mitis, S. intermedius and S. oralis at $24 \mathrm{~h}$ of incubation (Figure 2). However, by $48 \mathrm{~h}$ of incubation, cellular morphologies in all conditions seem comparable to each other and to control. To assess the viability of cells, trypan blue exclusion assays were performed. S. gordonii did not cause significant OKF6/Tert cell death after $1 \mathrm{~h}$ of bacterial exposure. However, this commensal did cause significant cell death after $2 \mathrm{~h}$ of exposure (Figure 3). Cells remained viable following challenge by S. intermedius at a MOI of 100 for up to $2 \mathrm{~h}$ (Figure 3). Exposure to $S$. oralis and $S$. mitis resulted in significant cell death after 1 and $2 \mathrm{~h}$ compared to untreated controls $(p<0.05)$. The effect of these two commensals is time-dependent as more cell death is observed over prolonged periods of challenge. In every case, OKF6 cells remained viable when exposed, for up to $2 \mathrm{~h}$, to the spent BHI media of any of the four strains. These results indicate that, under the conditions 
tested, cytotoxicity only occurs when three of the four streptococci are present and physically interacting for at least $2 \mathrm{~h}$ with the OKF6/Tert cells. Based on these results, the remainder of the study was performed using only $S$. gordonii and $S$. intermedius for up to $1 \mathrm{~h}$ of interaction.

$0 \mathrm{~h}$
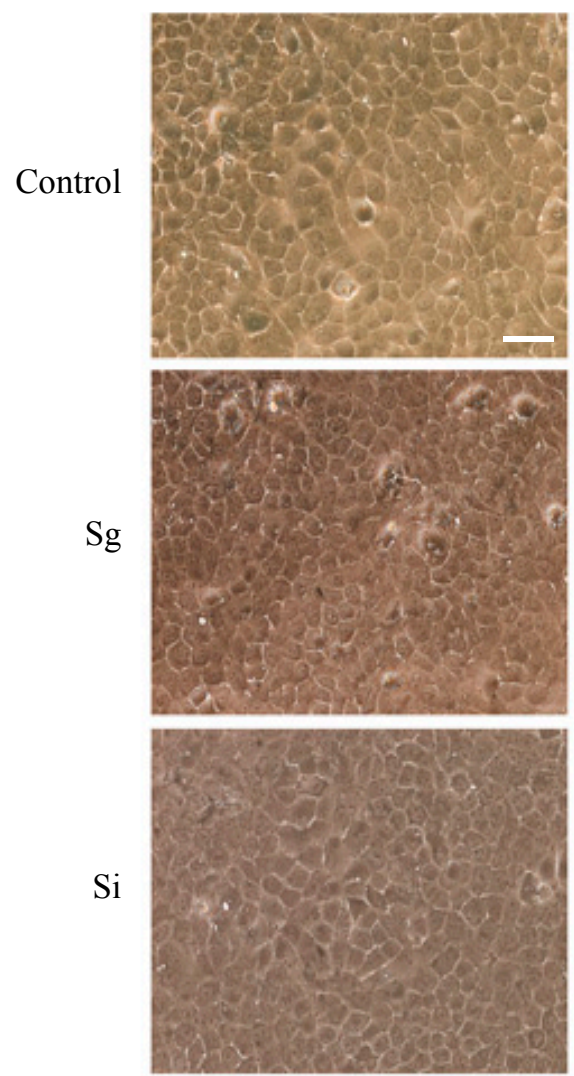

$\mathrm{Si}$

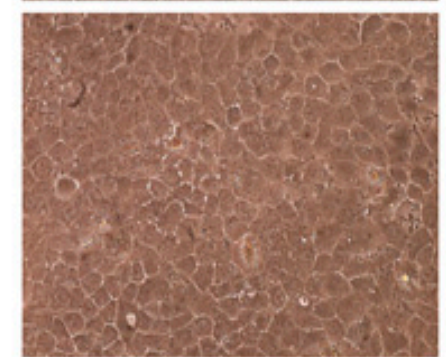

$\mathrm{Sm}$

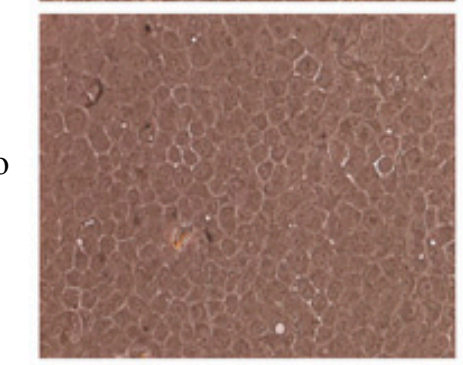

$24 \mathrm{~h}$
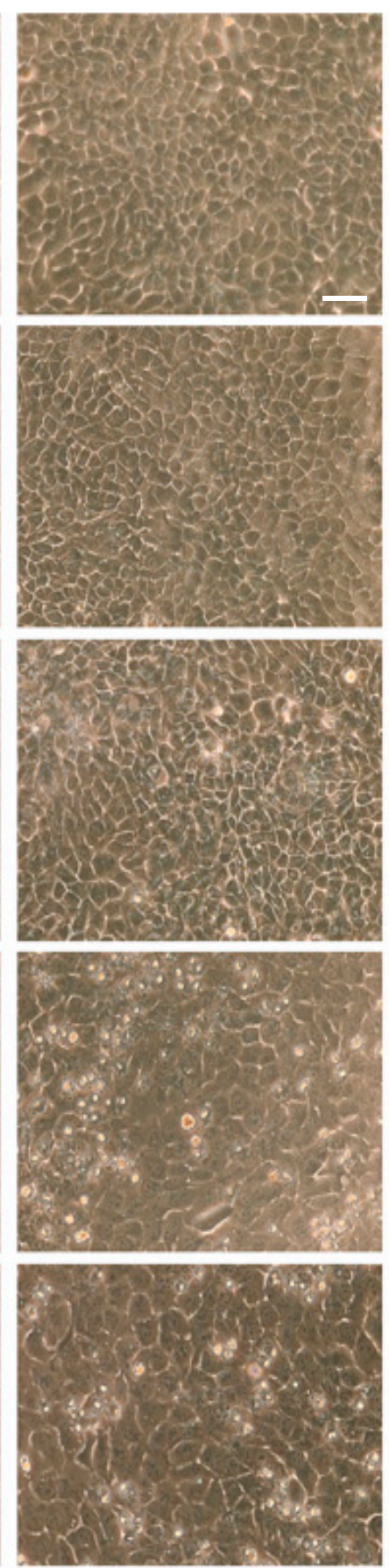

$48 \mathrm{~h}$
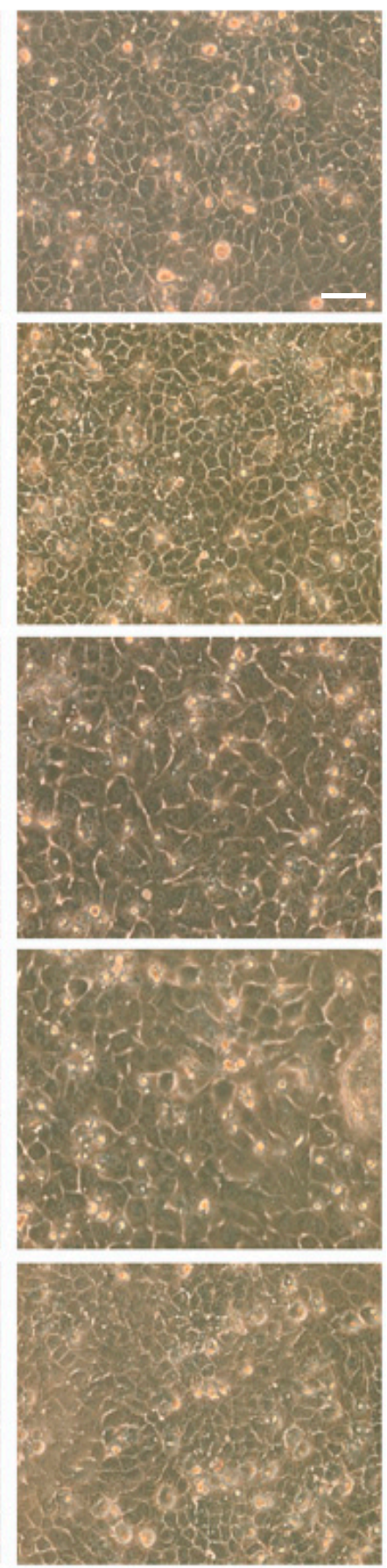

Figure 2. OKF6/Tert cellular morphology after exposure to S. gordonii (Sg), S. intermedius (Si), S. mitis $(\mathrm{Sm})$, and $\mathrm{S}$. oralis $(\mathrm{So})$ at $\mathrm{MOI}=100$ for $1 \mathrm{~h}$ of interaction. Light microscopy images were obtained at a magnification of $200 \times$. Bars $=100 \mu \mathrm{m}$. Representative images from three independent experiments. 


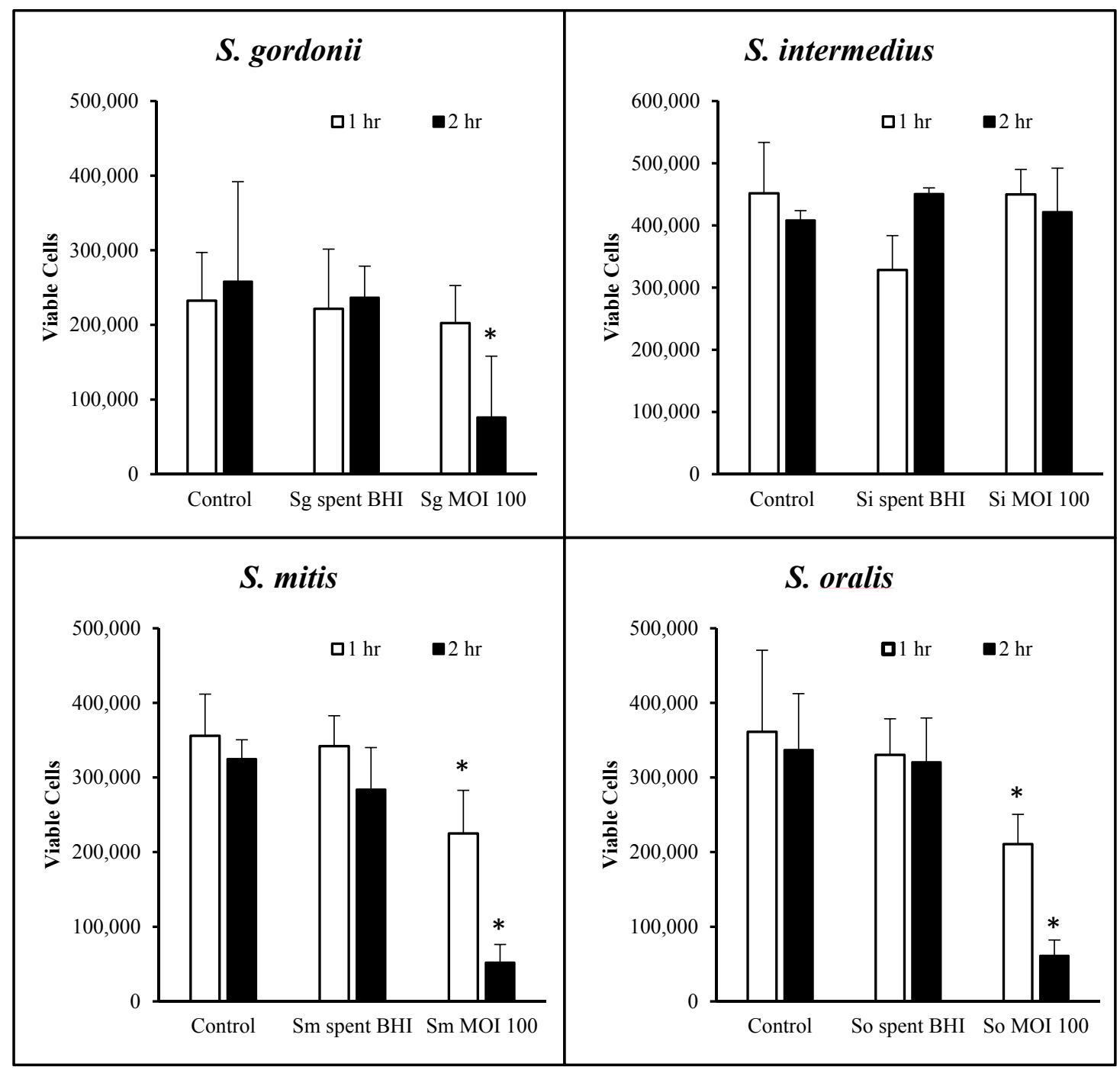

Figure 3. Viability of OKF6/Tert cells following exposure to commensal streptococci. Cell viability reflects the number of live OKF6 cells two days after exposure to S. gordonii (Sg), S. intermedius (Si), S. mitis (Sm), or S. oralis (So) or their spent media. Live cells were quantified using the trypan blue exclusion assay. Graphs represent the average and SD of four independent experiments. ${ }^{*}=p<0.05$ compared to control.

\subsection{Commensal Bacteria Adherence Assay}

OKF6/Tert cells were exposed to S. gordonii and S. intermedius. Figure 4 displays the total number of CFUs per well for both streptococci after incubation for $1 \mathrm{~h}$. Following thorough washing, 27,574 +/1539 CFUs of $S$. gordonii per well were recovered. Similarly, 30,203 +/- 4883 CFUs of S. intermedius were quantified after adherence to OKF6/Tert cells (Figure 4). This suggests that, when contrasting the number of OKF6/Tert cells per well in Figure 3 to the number of adhered CFUs per well, roughly one streptococcal CFU of either of these species adheres to every 10 to 15 cells on average (Figure 4). In addition, following antibiotic protection assays, an average of 96 or 99 CFUs of S. gordonii and S. intermedius, respectively, were found for every 100,000 host cells (data not shown). These results suggest that these two oral commensal streptococci invade at extremely low rates or not at all. 


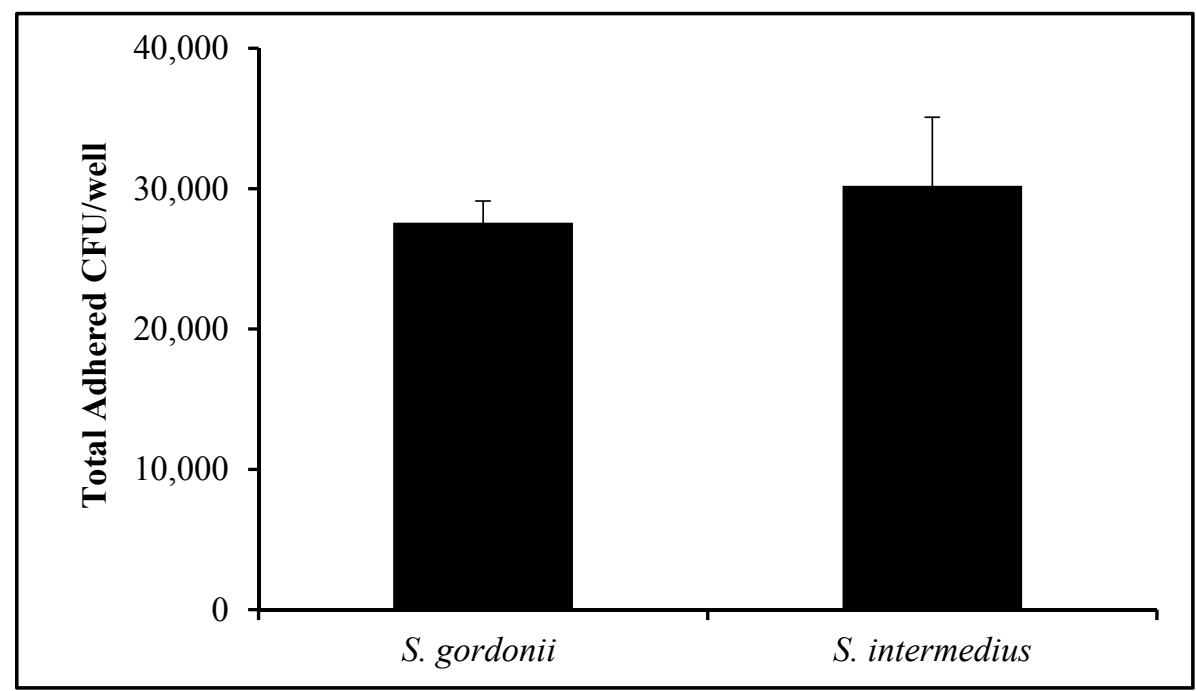

Figure 4. Adherence of commensal bacteria. Quantification of oral commensal streptococci CFUs after adherence to OKF6/Tert cells $(\mathrm{MOI}=100)$ in 24-well plates. Graph represents the average and SD of six independent experiments.

\subsection{P. gingivalis Invasion Post-Commensal Co-Cultures}

P. gingivalis 33277 invasion into OKF6/Tert cells is around 370,000 bacteria into about 300,000 to 400,000 cells/well, which makes the bacterium/cell ratio around 1:1 (Figure 5). This result agrees with the results obtained by others [28,41-43]. S. gordonii and S. intermedius pre-treatments of OKF6/Tert cells reduced $P$. gingivalis invasion to about $75 \%$ and $40 \%$, respectively (Figure 5). In addition, S. intermedius treatment reduced the amount of $P$. gingivalis invasion into OKF6/Tert cells significantly less than $S$. gordonii treatment ( $p$ value $<0.05$ ). Our results indicate that during the host-bacteria interactions of OKF6/Tert cells with either commensal, $P$. gingivalis invasion is significantly reduced.

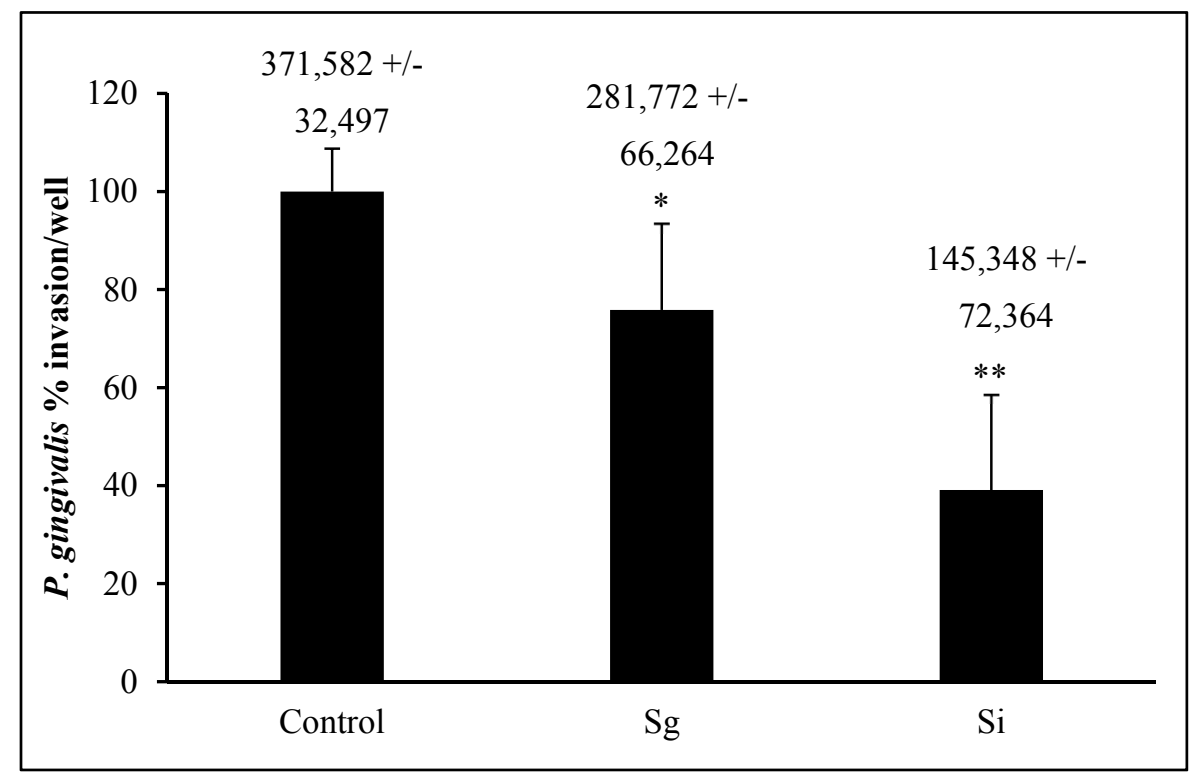

Figure 5. Invasion of $P$. gingivalis following exposure to commensal bacteria. Percentage of $P$. gingivalis CFUs (absolute values +/- SD above each bar) that invaded OKF6/Tert cells after exposure to $S$. gordonii $(\mathrm{Sg})$ or S. intermedius $(\mathrm{Si})$. All bacteria were added to OKF6/Tert cells at MOI $=100$. Graph represents the average and SD of four independent experiments. ${ }^{*}=p<0.05$ compared to control. ${ }^{* *}=p<0.05$ compared to control and Sg. 


\subsection{Commensal Antagonistic Properties against P. gingivalis}

Figure 6 shows S. gordonii and S. intermedius's inhibiting effects on P. gingivalis. E. coli, which has already been shown to have no effect on the growth of $P$. gingivalis [20], and TSBY (outlined in the black circle) were used as negative controls for inhibitory effects. Both oral commensal streptococci show antagonistic relationships with $P$. gingivalis, as indicated by the white arrows pointing at the areas of growth inhibition. Note that these areas are directly in front of the oral commensal streptococci spots. These results suggest that $S$. gordonii and $S$. intermedius produce inhibitory substances that diffuse through the medium and inhibit $P$. gingivalis growth. This antagonism may be related to the commensal streptococci's ability to decrease P. gingivalis invasion into the OKF6/Tert cells (Figure 5).
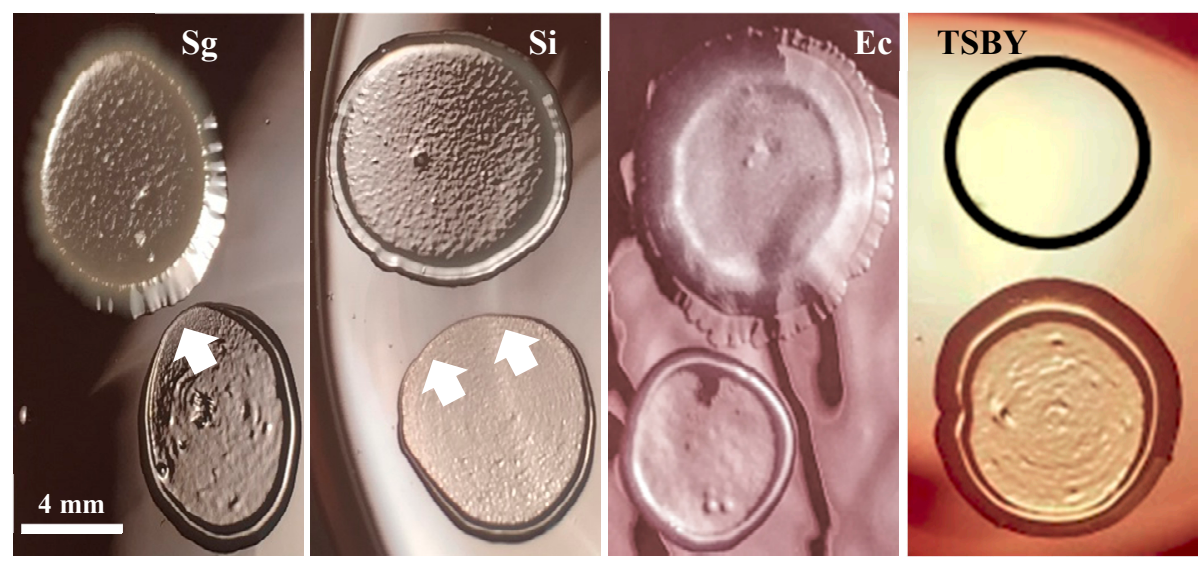

Figure 6. S. gordonii and S. intermedius antagonism against $P$. gingvalis. All bacteria were diluted in TSBY before plating. Spots for S. gordonii (Sg), S. intermedius (Si), E. coli (Ec), diluted 1:100, or TSBY are shown on the top of each image. Spots for $P$. gingivalis, diluted 1:10, are shown at the bottom of every image. White arrows point at areas of $P$. gingivalis spots with growth inhibition. Representative images from three independent experiments.

\section{Discussion}

Overall, our study demonstrates that commensal bacteria can provide a protective effect for the host in the context of pathogenic invasion. The specific mechanisms of commensal bacterial protection remain unknown. However, these mechanisms may serve as additional therapeutic methods to treat PD.

KSFM was used as the vehicle for bacteria to establish the MOI throughout the study. KSFM does support the growth of all commensals tested, albeit at a much slower pace than BHI. Therefore, some bacterial growth is expected to occur during the interaction with the host, and this may cause the MOI values to deviate slightly throughout the experiments. Interestingly, S. gordonii and S. intermedius are the commensal strains that grow the fastest and slowest, respectively (Figure 1). However, neither of these species appears to be harmful to the host within the first hour of host-bacteria interactions (Figure 3). Furthermore, even though S. intermedius can be expected to exist in lower quantities than S. gordonii, by the end of the hour of host-bacteria interactions, both species were bound to the host at similar levels (Figure 4). Nonetheless, S. intermedius is the strain that confers the best protection to the host cells (Figure 5).

Figure 2 shows that the cellular morphology of OKF6/Tert cells does not seem to change significantly after one hour of interactions. However, S. oralis and S. mitis lead to the substantial death of OKF6/Tert cells after the same treatment (Figure 3). The spent media of all commensals tested, on the other hand, did not harm the host cells, which may suggest that the death of OKF6/Tert cells requires direct contact or the activity of the species near the host. We tested the possibility of streptococcal invasion into OKF6/Tert cells (data not shown) and found extremely low levels to no invasion at all. We propose that the commensal strains S. gordonii and S. intermedius do not invade OKF6/Tert cells, which is in agreement with the little to no invasion observed with S. gordonii by others [26]. Interestingly, 
since S. mitis and S. oralis are cytotoxic, it is unclear if cells exposed to these bacteria may be more susceptible to $P$. gingivalis invasion or how this dynamic may affect the development of PD.

The methodology of CFU counts was used primarily because of its reliability in counting the live bacteria harvested at the end of every experiment. Quantitative PCR can also take account of the total bacteria per well but with the limitation of including live and dead bacteria. For example, commensal bacteria that are bound to OKF6/Tert cells and undergo antibiotic protection assays will still contain DNA, which will still be amplified during the qPCR assay. Similarly, in fluorescence-based microscopy techniques, fluorescent labels would not distinguish between live and dead bacteria, and therefore, the microscopic images would present all bacteria associated with OKF6/Tert cells. Because of the limitations of all those other techniques, we chose CFU counts as a dependable method for measuring live bacteria only.

Streptococci CFUs do not necessarily reflect one bacterium, but often a chain of bacteria that may include 10 to 20 streptococci. This explains the CFU/cell ratio of roughly $1 \mathrm{CFU}$ corresponding to roughly 10 to 15 host cells, which means that a given chain of commensal bacteria could have been bound to one of every twelve cells on average. It becomes plausible that several commensal bacteria in a chain are blocking potential $P$. gingivalis receptors, decreasing pathogenic invasion into the host cells. However, this does not explain the decrease in invasion in the neighboring host cells. In order to decrease invasion, other mechanisms must be in place to prevent $P$. gingivalis from entering these host cells. Such mechanisms of streptococcal host protection from $P$. gingivalis invasion remain unknown.

Figure 6 demonstrates that both S. gordonii and S. intermedius have antagonistic relationships with P. gingivalis. These results are in concordance with the results of Herrero et al., where S. gordonii inhibited $P$. gingivalis growth via the production of hydrogen peroxide. Herrero et al. report the production of peroxide by several species of oral commensal bacteria, inhibiting the growth of pathogens including P. gingivalis, Aggregatibacter actinomycetemcomitans, and Prevotella intermedia [20]. In accordance, we also report S. gordonii and S. intermedius's inhibition of $P$. gingivalis growth (Figure 6), which could suggest a putative mechanism by which peroxide production may deter $P$. gingivalis from approaching the host. An additional mechanism could be the streptococcal binding to and concealing of common host receptors. In order to address this point, studies aiming to (i) identify the surface molecules on S. intermedius that serve as anchoring agents for host epithelial tissues and (ii) add these surface molecules to the host in competition assays with P. gingivalis may be considered. Molecules from a commensal species that prevent the colonization and invasion of $P$. gingivalis may be used to enhance therapies for PD. Lastly, in healthy individuals who maintain good oral health, commensal streptococci create a beneficial oral biofilm that contributes to the host immune response $[19,44]$. Therefore, it is possible that these commensal species are protective against the invasion of pathogens in vivo.

Our study agrees with other studies where commensal bacteria work in cooperation with the host to inhibit the pathogenesis of disease-causing bacteria [45,46]. For example, several species of commensal gut bacteria show protective effects against airway infections by Klebsiella pneumoniae and Streptococcus pneumoniae [47]. An interesting study demonstrates that Akkermansia muciniphila from the gut decreases $P$. gingivalis-based periodontitis in vivo [48]. Furthermore, S. gordonii itself promotes the improvement of the epithelial barrier (tight junctions) [39], as well as the expression of cytokines, human defensins, and other immunological mediators $[26,44,49,50]$. Our results align well with other studies demonstrating that commensal bacteria can slow pathogenic activity.

Cytokine production could be an important parameter to measure. However, we feel that it falls outside of the aim of this study because cytokines are relevant to the cellular immune response. Our study is most concerned with the interactions between commensal bacteria and the host leading to protection from invasive P. gingivalis. Several other studies address this inquiry $[26,38,44,51-54]$

In conclusion, we have observed that $S$. gordonii and S. intermedius do not cause cell death when compared to the other two commensal species tested. Both species adhere to our oral epithelial cell model and significantly decrease the invasion of periodontopathogen $P$. gingivalis, offering protection 
to the host. S. intermedius reduced P. gingivalis invasion by more than $60 \%$. The mechanisms of this protective effect are still unknown.

The invasion of $P$. gingivalis plays a large role in the initiation and progression of PD and therefore the oral health of individuals [55]. Oral health is important in maintaining overall health [15,56-58]. At a higher risk for PD, Americans 65 years of age and older may experience tooth loss, pain, discomfort, the inability to properly chew and swallow food, and ultimately poor nutrition [2]. The role of $P$. gingivalis in systemic diseases further heightens the gravity of this pathogen. Our work is innovative in the context of using the oral commensal microbiota against pathogens such as $P$. gingivalis in an effort to decrease the chances of periodontal disease.

Author Contributions: Conceptualization, G.A.C.; Methodology, G.A.C. and A.N.H.; Formal analysis, G.A.C.; Investigation, A.N.H., H.M.H., M.G.J.; Writing-Original Draft Preparation, A.N.H. and G.A.C.; Writing-Review and Editing, G.A.C., A.N.H., H.M.H., M.G.J.; Funding Acquisition, G.A.C. All authors have read and agreed to the published version of the manuscript.

Funding: This work was supported by the biology department at Muhlenberg College, Allentown, PA 18104. This research received no external funding.

Acknowledgments: The authors would like to thank faculty members from the biology department at Muhlenberg College and Dominic Palazzolo from Lincoln Memorial University for their assistance in the preparation of this manuscript.

Conflicts of Interest: The authors declare no conflict of interest. The funders had no role in the design of the study; in the collection, analyses, or interpretation of data; in the writing of the manuscript, or in the decision to publish the results.

\section{References}

1. Periodontal Disease Division of Oral Health CDC. Available online: https://www.cdc.gov/oralhealth/periodo ntal_disease/index.htm (accessed on 23 May 2018).

2. Eke, P.I.; Wei, L.; Borgnakke, W.; Zhang, X.; McGuire, L.C.; Genco, R.J.; Thornton-Evans, G.; Lu, H. Periodontitis prevalence in adults? 65 years of age, in the USA. Periodontology 2000 2016, 72, 76-95. [CrossRef] [PubMed]

3. Periodontitis: MedlinePlus Medical Encyclopedia. Available online: https://medlineplus.gov/ency/article/0 01059.htm (accessed on 23 May 2018).

4. Parahitiyawa, N.B.; Jin, L.J.; Leung, W.; Yam, W.C.; Samaranayake, L.P. Microbiology of Odontogenic Bacteremia: Beyond Endocarditis. Clin. Microbiol. Rev. 2009, 22, 46-64. [CrossRef] [PubMed]

5. Kumar, P. Oral microbiota and systemic disease. Anaerobe 2013, 24, 90-93. [CrossRef] [PubMed]

6. Seymour, G.; Ford, P.J.; Cullinan, M.; Leishman, S.; Yamazaki, K. Relationship between periodontal infections and systemic disease. Clin. Microbiol. Infect. 2007, 13, 3-10. [CrossRef] [PubMed]

7. Zhou, X.; Han, J.; Liu, Z.; Song, Y.; Wang, Z.; Sun, Z. Effects of periodontal treatment on lung function and exacerbation frequency in patients with chronic obstructive pulmonary disease and chronic periodontitis: A 2-year pilot randomized controlled trial. J. Clin. Periodontol. 2014, 41, 564-572. [CrossRef]

8. Wu, Z.; Nakanishi, H. Lessons from Microglia Aging for the Link between Inflammatory Bone Disorders and Alzheimer's Disease. Available online: https://www.hindawi.com/journals/jir/2015/471342/ (accessed on 12 June 2018).

9. Scannapieco, F. The oral microbiome: Its role in health and in oral and systemic infections. Clin. Microbiol. Newsl. 2013, 35, 163-169. [CrossRef]

10. Borgnakke, W.; Ylöstalo, P.V.; Taylor, G.W.; Genco, R.J. Effect of periodontal disease on diabetes: Systematic review of epidemiologic observational evidence. J. Clin. Periodontol. 2013, 40, 135-152. [CrossRef]

11. Gaur, S.; Agnihotri, R. Alzheimer's disease and chronic periodontitis: Is there an association? Geriatr. Gerontol. Int. 2014, 15, 391-404. [CrossRef]

12. Singhrao, S.K.; Harding, A.; Poole, S.; Kesavalu, L.; Crean, S. Porphyromonas Gingivalis Periodontal Infection and Its Putative Links with Alzheimer's Disease. Available online: https:/www.hindawi.com/journals/mi/20 15/137357/ (accessed on 12 June 2018). 
13. Ho, M.-H.; Lamont, R.J.; Xie, H. Identification of Streptococcus cristatus peptides that repress expression of virulence genes in Porphyromonas gingivalis. Sci. Rep. 2017, 7, 1413. [CrossRef]

14. Hajishengallis, G.; Liang, S.; Payne, M.A.; Hashim, A.; Jotwani, R.; Eskan, M.A.; McIntosh, M.L.; Alsam, A.; Kirkwood, K.L.; Lambris, J.D.; et al. Low-Abundance Biofilm Species Orchestrates Inflammatory Periodontal Disease through the Commensal Microbiota and Complement. Cell Host Microbe 2011, 10, 497-506. [CrossRef]

15. Tribble, G.; Lamont, R.J. Bacterial invasion of epithelial cells and spreading in periodontal tissue. Periodontology 2000 2010, 52, 68-83. [CrossRef] [PubMed]

16. Hoppe, T.; Kraus, D.; Probstmeier, R.; Jepsen, S.; Winter, J. Stimulation with Porphyromonas gingivalis enhances malignancy and initiates anoikis resistance in immortalized oral keratinocytes. J. Cell. Physiol. 2019, 234, 21903-21914. [CrossRef]

17. Lamont, R.J.; El-Sabaeny, A.; Park, Y.; Cook, G.S.; Costerton, J.W.; DeMuth, D.R. Role of the Streptococcus gordonii SspB protein in the development of Porphyromonas gingivalis biofilms on streptococcal substrates. Microbiology 2002, 148, 1627-1636. [CrossRef] [PubMed]

18. Park, Y.; Simionato, M.R.; Sekiya, K.; Murakami, Y.; James, D.; Chen, W.; Hackett, M.; Yoshimura, F.; DeMuth, D.R.; Lamont, R. Short Fimbriae of Porphyromonas gingivalis and Their Role in Coadhesion with Streptococcus gordonii. Infect. Immun. 2005, 73, 3983-3989. [CrossRef] [PubMed]

19. Gutt, B.; Ren, Q.; Hauser-Gerspach, I.; Kardas, P.; Stübinger, S.; Astasov-Frauenhoffer, M.; Waltimo, T. Beneficial Oral Biofilms as Smart Bioactive Interfaces. Front. Microbiol. 2018, 9, 9. [CrossRef] [PubMed]

20. Herrero, E.R.; Slomka, V.; Bernaerts, K.; Boon, N.; Hernandez-Sanabria, E.; Passoni, B.B.; Quirynen, M.; Teughels, W. Antimicrobial effects of commensal oral species are regulated by environmental factors. J. Dent. 2016, 47, 23-33. [CrossRef]

21. Handfield, M.; Mans, J.J.; Zheng, G.; Lopez, M.C.; Mao, S.; Progulske-Fox, A.; Narasimhan, G.; Baker, H.V.; Lamont, R.J. Distinct transcriptional profiles characterize oral epithelium-microbiota interactions. Cell. Microbiol. 2005, 7, 811-823. [CrossRef]

22. Hasegawa, Y.; Mans, J.J.; Mao, S.; Lopez, M.C.; Baker, H.V.; Handfield, M.; Lamont, R.J. Gingival Epithelial Cell Transcriptional Responses to Commensal and Opportunistic Oral Microbial Species. Infect. Immun. 2007, 75, 2540-2547. [CrossRef]

23. Rosan, B.; Lamont, R.J. Dental plaque formation. Microbes Infect. 2000, 2, 1599-1607. [CrossRef]

24. Facklam, R. What Happened to the Streptococci: Overview of Taxonomic and Nomenclature Changes. Clin. Microbiol. Rev. 2002, 15, 613-630. [CrossRef]

25. Colombo, A.V.; Da Silva, C.M.; Haffajee, A.; Colombo, A.P.V. Identification of intracellular oral species within human crevicular epithelial cells from subjects with chronic periodontitis by fluorescence in situ hybridization. J. Periodontal Res. 2007, 42, 236-243. [CrossRef] [PubMed]

26. Dickinson, B.C.; Moffatt, C.E.; Hagerty, D.; Whitmore, S.E.; A Brown, T.; Graves, D.T.; Lamont, R.J. Interaction of oral bacteria with gingival epithelial cell multilayers. Mol. Oral Microbiol. 2011, 26, 210-220. [CrossRef] [PubMed]

27. Lee, K.; Roberts, J.S.; Choi, C.H.; Atanasova, K.; Yilmaz, Ö. Porphyromonas gingivalis traffics into endoplasmic reticulum-rich-autophagosomes for successful survival in human gingival epithelial cells. Virulence 2018, 9, 845-859. [CrossRef] [PubMed]

28. Lamont, R.J.; Chan, A.; Belton, C.M.; Izutsu, K.T.; Vasel, D.; Weinberg, A. Porphyromonas gingivalis invasion of gingival epithelial cells. Infect. Immun. 1995, 63, 3878-3885. [CrossRef] [PubMed]

29. Yilmaz, Ö.; Watanabe, K.; Lamont, R.J. Involvement of integrins in fimbriae-mediated binding and invasion by Porphyromonas gingivalis. Cell. Microbiol. 2002, 4, 305-314. [CrossRef] [PubMed]

30. Nakagawa, I.; Amano, A.; Kuboniwa, M.; Nakamura, T.; Kawabata, S.; Hamada, S. Functional Differences among FimA Variants of Porphyromonas gingivalis and Their Effects on Adhesion to and Invasion of Human Epithelial Cells. Infect. Immun. 2002, 70, 277-285. [CrossRef]

31. Cugini, C.; Stephens, D.N.; Nguyen, D.; Kantarci, A.; Davey, M.E. Arginine deiminase inhibits Porphyromonas gingivalis surface attachment. Microbiology 2013, 159, 275-285. [CrossRef]

32. Xie, H.; Hong, J.; Sharma, A.; Wang, B. Streptococcus cristatus ArcA interferes with Porphyromonas gingivalis pathogenicity in mice. J. Periodontal Res. 2012, 47, 578-583. [CrossRef]

33. Christopher, A.B.; Arndt, A.; Cugini, C.; Davey, M.E. A streptococcal effector protein that inhibits Porphyromonas gingivalis biofilm development. Microbiology 2010, 156, 3469-3477. [CrossRef] 
34. Wang, B.-Y.; Wu, J.; Lamont, R.J.; Lin, X.; Xie, H. Negative Correlation of Distributions of Streptococcus cristatus and Porphyromonas gingivalis in Subgingival Plaque. J. Clin. Microbiol. 2009, 47, 3902-3906. [CrossRef]

35. Kreth, J.; Zhang, Y.; Herzberg, M.C. Streptococcal Antagonism in Oral Biofilms: Streptococcus sanguinis and Streptococcus gordonii Interference with Streptococcus mutans. J. Bacteriol. 2008, 190, 4632-4640. [CrossRef] [PubMed]

36. Wang, B.-Y.; Kuramitsu, H.K. Interactions between Oral Bacteria: Inhibition of Streptococcus mutans Bacteriocin Production by Streptococcus gordonii. Appl. Environ. Microbiol. 2005, 71, 354-362. [CrossRef]

37. Sukeno, A.; Nagamune, H.; Whiley, R.A.; Jafar, S.I.; Opoku, A.; Ohkura, K.; Maeda, T.; Hirota, K.; Miyake, Y.; Kourai, H. Intermedilysin Is Essential for the Invasion of Hepatoma HepG2 Cells byStreptococcus intermedius. Microbiol. Immunol. 2005, 49, 681-694. [CrossRef]

38. Nagata, E.; De Toledo, A.; Oho, T. Invasion of human aortic endothelial cells by oral viridans group streptococci and induction of inflammatory cytokine production. Mol. Oral Microbiol. 2010, 26, 78-88. [CrossRef] [PubMed]

39. Ye, P.; Harty, D.; Commandeur, Z.; Hunter, N. Binding of Streptococcus gordonii to oral epithelial monolayers increases paracellular barrier function. Microb. Pathog. 2013, 56, 53-59. [CrossRef] [PubMed]

40. Brice, D.C.; Figgins, E.; Yu, F.; Diamond, G. Type I interferon and interferon-stimulated gene expression in oral epithelial cells. Mol. Oral Microbiol. 2019, 34, 245-253. [CrossRef]

41. Ho, M.-H.; Lamont, R.J.; Xie, H. A novel peptidic inhibitor derived from Streptococcus cristatus ArcA attenuates virulence potential of Porphyromonas gingivalis. Sci. Rep. 2017, 7, 16217. [CrossRef]

42. Saito, A.; Inagaki, S.; Ishihara, K. Differential ability of periodontopathic bacteria to modulate invasion of human gingival epithelial cells by Porphyromonas gingivalis. Microb. Pathog. 2009, 47, 329-333. [CrossRef]

43. Jauregui, C.; Robinson, B.; De Moya, A.V.; Brockman, R.D.; Roman, A.V.; Cash, M.N.; Culp, D.J.; Lamont, R.J. Establishment and characterization of a telomerase immortalized human gingival epithelial cell line. J. Periodontal Res. 2013, 48, 713-721. [CrossRef]

44. Dommisch, H.; Reinartz, M.; Backhaus, T.; Deschner, J.; Chung, W.; Jepsen, S. Antimicrobial responses of primary gingival cells to Porphyromonas gingivalis. J. Clin. Periodontol. 2012, 39, 913-922. [CrossRef]

45. O'Callaghan, A.; Corr, S. Establishing Boundaries: The Relationship That Exists between Intestinal Epithelial Cells and Gut-Dwelling Bacteria. Microorganisms 2019, 7, 663. [CrossRef] [PubMed]

46. Dumas, A.; Bernard, L.; Poquet, Y.; Lugo-Villarino, G.; Neyrolles, O. The role of the lung microbiota and the gut-lung axis in respiratory infectious diseases. Cell. Microbiol. 2018, 20, e12966. [CrossRef] [PubMed]

47. Brown, R.L.; Sequeira, R.P.; Clarke, T.B. The microbiota protects against respiratory infection via GM-CSF signaling. Nat. Commun. 2017, 8, 1512. [CrossRef] [PubMed]

48. Huck, O.; Mulhall, H.; Rubin, G.; Kizelnik, Z.; Iyer, R.; Perpich, J.D.; Haque, N.; Cani, P.D.; De Vos, W.M.; Amar, S. Akkermansia muciniphila reduces Porphyromonas gingivalis -induced inflammation and periodontal bone destruction. J. Clin. Periodontol. 2019, 47, 202-212. [CrossRef] [PubMed]

49. Ji, S.; Kim, Y.; Min, B.-M.; Han, S.H.; Choi, Y. Innate immune responses of gingival epithelial cells to nonperiodontopathic and periodontopathic bacteria. J. Periodontal Res. 2007, 42, 503-510. [CrossRef]

50. Chung, W.O.; Dale, B.A. Innate Immune Response of Oral and Foreskin Keratinocytes: Utilization of Different Signaling Pathways by Various Bacterial Species. Infect. Immun. 2004, 72, 352-358. [CrossRef]

51. Sliepen, I.; Van Damme, J.; Van Essche, M.; Loozen, G.; Quirynen, M.; Teughels, W. Microbial Interactions Influence Inflammatory Host Cell Responses. J. Dent. Res. 2009, 88, 1026-1030. [CrossRef]

52. Peyyala, R.; Kirakodu, S.S.; Novak, K.F.; Ebersole, J.L. Oral epithelial cell responses to multispecies microbial biofilms. J. Dent. Res. 2013, 92, 235-240. [CrossRef]

53. Stathopoulou, P.G.; Benakanakere, M.R.; Galicia, J.C.; Kinane, D.F. Epithelial cell pro-inflammatory cytokine response differs across dental plaque bacterial species. J. Clin. Periodontol. 2010, 37, 24-29. [CrossRef]

54. Zhang, G.; Chen, R.; Rudney, J. Streptococcus cristatus attenuates Fusobacterium nucleatum-induced interleukin-8 expression in oral epithelial cells. J. Periodontal Res. 2008, 43, 408-416. [CrossRef]

55. Lamont, R.J.; Jenkinson, H.F. Life Below the Gum Line: Pathogenic Mechanisms ofPorphyromonas gingivalis. Microbiol. Mol. Boil. Rev. 1998, 62, 1244-1263. [CrossRef]

56. Daalderop, L.; Wieland, B.; Tomsin, K.; Reyes, L.; Kramer, B.; Vanterpool, S.; Been, J.V. Periodontal Disease and Pregnancy Outcomes: Overview of Systematic Reviews. JDR Clin. Transl. Res. 2017, 3, 10-27. [CrossRef] [PubMed] 
57. Hajishengallis, G.; Lamont, R.J. Beyond the red complex and into more complexity: The polymicrobial synergy and dysbiosis (PSD) model of periodontal disease etiology. Mol. Oral Microbiol. 2012, 27, 409-419. [CrossRef] [PubMed]

58. Holmlund, A.; Lampa, E.; Lind, L. Oral health and cardiovascular disease risk in a cohort of periodontitis patients. Atherosclerosis 2017, 262, 101-106. [CrossRef] [PubMed]

(C) 2020 by the authors. Licensee MDPI, Basel, Switzerland. This article is an open access article distributed under the terms and conditions of the Creative Commons Attribution (CC BY) license (http://creativecommons.org/licenses/by/4.0/). 